\title{
Effect of non surgical periodontal therapy on salivary and RBC lysate superoxide dismutase levels in periodontitis: A clinico biochemical study
}

\author{
Parth, Purwar ${ }^{1}$, Jaya, Dixit ${ }^{1}$, Abbas Ali, Mahdi ${ }^{2}$, Sagar, Sareen ${ }^{1}$ \\ ${ }^{I}$ Department of Periodontology, Faculty of Dental Sciences, King George's Medical University, Lucknow, \\ Uttar Pradesh, India. \\ ${ }^{2}$ Department of Biochemistry, King George's Medical University, Lucknow, Uttar Pradesh, India.
}

\begin{abstract}
To compute superoxide dismutase (SOD) levels in saliva and plasma of chronic periodontitis patients as compared to healthy controls, to find the association, if any, with clinical parameters and to verify the role of non surgical periodontal therapy (NSPT) in amending SOD activity.

Forty two subjects were divided into two groups based on periodontal parameters; Group A: 20 chronic periodontitis patients (CP) and Group B: 22 periodontally healthy controls (PH).Clinical parameters, saliva samples (modified draining method) and plasma samples (by venipuncture) were evaluated at baseline, at 3 months and 6 months after NSPT for changes in clinical parameters and SOD activity. SOD levels were determined by Mc Cord and Fridovich method and absorbance was read by spectrophotometer at $560 \mathrm{~nm}$.

Significantly lower levels of salivary and plasma SOD $(p<0.05)$ were detected in CP patients with a negative co-relation with clinical parameters at baseline in group-A. Post therapy SOD levels increased significantly $(p<0.05)$ and plasma SOD levels rose even above that of control group.
\end{abstract}

Keywords: Chronic periodontitis, Non surgical periodontal therapy, Oxidative stress, Plasma, Saliva, Superoxide dismutase.

\section{Introduction}

Reactive oxygen species (ROS), oxidative stress (OS) and periodontitis have together emerged as a case plagued with perplexities and maintenance of physiological levels of antioxidants (AO) seems to be the cure to it.

ROS, chemically reactive molecules containing oxygen, produced as a natural byproduct have formidable roles in cell signaling and homeostasis (1). ROS includes oxygen derived free radicals, namely superoxide $\left(\mathrm{O}_{2}{ }^{*}\right)$, hydroxyl $\left(\mathrm{OH}^{*}\right)$, nitric oxide $(\mathrm{NO})$, and non-radical derivatives of oxygen, namely hydrogen peroxide $\left(\mathrm{H}_{2} \mathrm{O}_{2}\right)$ and hypochlorous acid $(\mathrm{HOCl})$.

Physiologically a state of dynamic stability prevails between ROS and antioxidants activity, which when shifts in favor of ROS, OS ensues. Oxidative stress leads to potential damage in the form of array of human diseases associated with hyper-inflammation such as arthritis, adult respiratory distress syndrome, heart diseases, stroke, acquired immunodeficiency syndrome (AIDS), Alzheimer's disease, Parkinson's disease (2) and periodontal diseases (3).

Periodontitis, a chronic inflammatory disease of tooth supporting structures is characterized by gingival bleeding, periodontal pocket formation, destruction of connective tissue attachment and alveolar bone loss (4). The emergence of pathogenic sub-gingival plaque biofilm and an inappropriate host response in a susceptible individual, results in progressive destruction of periodontal tissues leading to tooth loss (5). Susceptibility appears largely due to a phenotype characterized by an exaggerated, "hyper inflammatory" response to the colonizing bacteria (6). The production of ROS by polymorphonuclear leucocytes (PMN's) is the primary means of killing bacteria; however, the extracellular release of ROS results in destruction of the surrounding tissues $(7,8)$.

Role of ROS in periodontal tissue destruction has been comprehensively discussed by Gustafson et al (9), Panjamurthy et al (10), Buduneli et al (11) and Akalin et al (12). Excessive production of ROS can cause: lysis of cell membrane, inactivation of proteolytic enzyme inhibitors e.g. tissue inhibitor of matrix 
metalloproteinase (TIMP) and $\alpha-1$ antiproteinase, activation of proteolytic enzymes such as collagenase, gelatinase and matrix metalloproteinase (MMP) resulting in collagenolysis (13). ROS may also lead to stimulation of pro-inflammatory cytokine release via.activating nuclear factor- $\mathrm{k} \beta$ (3). Thus, the larger upward shift in the pro-oxidant status, intracellularly, brings about direct damage to vital biomolecules, which ultimately causes cell death (by necrosis or accelerated apoptosis), and extracellularly cause direct connective tissue damage and destruction of extracellular matrices and their components (14). However, it still remains a dilemma whether excess production of ROS in periodontitis patients is a cause or effect of the disease process.

It is estimated that $1-3$ billion reactive species are generated per cell per day, therefore the importance of AO defense systems in the maintenance of health becomes clear (15). Antioxidants are defined as those substances which when present at low concentrations, compared to those of an oxidizable substrate, will significantly delay or inhibit oxidation of that substrate (16). Studies have shown that periodontitis patients have compromised anti oxidant defense in plasma $(10,17,18)$, saliva $(3,19), \operatorname{GCF}(17,20)$ and gingival biopsy samples $(21,22)$.

Oxidative killing of invading periopathogens leads to generation of highly toxic reactive oxygen metabolite $(\mathrm{ROM})$ - the superoxide anion $\left(\mathrm{O}^{-*}\right)$. Superoxide anion formed, either dismutates spontaneously (a rapid reaction at $\mathrm{pH}$ 7.4) or is actively converted to hydrogen peroxide $\left(\mathrm{H}_{2} \mathrm{O}_{2}\right)$ by one of the three superoxide dismutase enzyme systems. SOD, a preventative, metal ion sequestrator, anti oxidant enzyme has been regarded as the most significant $\mathrm{AO}$ within mammalian tissues $(23,24)$. SOD exists in three forms based on the associated co-factored metal ion namely SOD 1: $\mathrm{Cu}^{2+} / \mathrm{Zn}^{2+}$ found within cytosol, SOD 2: $\mathrm{Mn}^{2+}$ found within mitochondria, SOD 3: Extracellular $\mathrm{Cu}^{2+} / \mathrm{Zn}^{2+}$ SOD.The concentration of SOD differs in various body compartments in health and disease. SOD concentration has been evaluated in periodontitis subjects but the results have been indecisive $(22,25,26,27)$.

Grant et al,(28) Wei et al,(29) and Singh et al,(30) reported that NSPT normalized the AO levels in GCF, saliva and serum.

There is a paucity of literature delineating the exact role of SOD in periodontal heath and disease. Hence, the aim of the present study is three fold: to assess the concentration of SOD in saliva and plasma (RBC lysate), to find the association, if any, with periodontal health and disease and to evaluate effectiveness of non surgical periodontal therapy(NSPT) in restoring physiological SOD levels.

\section{(A) Study groups and designs:}

\section{Materials And Methods}

This longitudinal interventional human clinical study was undertaken by the Department of Periodontology \& Department of Biochemistry, King George's Medical University, Lucknow, U.P. India. This study was performed in two sections. First, a cross-sectional study, to investigate the levels of salivary and plasma SOD activity in CP patients compared to healthy controls and second, a longitudinal interventional study, to investigate the effectiveness of non surgical periodontal therapy on local and systemic SOD activity in CP patients. The study protocol was carried out in accordance with the ethical standards outlined in the 1964 Declaration of Helsinki, revised in 2008. The Ethics committee, King George's Medical University, Lucknow, U.P, India approved the study protocol. Before initiating the study each patient was informed about the purpose and design of the study. An informed consent in the native language and a thorough medical and dental history was taken from all the participants.

A total of 50 systemically healthy subjects were divided into two groups- Group A and Group-B each having 25 subjects. Only Group A subjects received periodontal therapy and was followed up at 3 and 6 months period after the intervention. A total of 20 subjects in Group A completed the study, while in Group-B, 3 subjects were excluded from the study since they did not adhere to the pre sample collection protocol.

Inclusion criteria for Group-A were presence of clinical gingival inflammation, clinical attachment loss (CA loss) $>1 \mathrm{~mm}$, probing pocket depth (PPD) $\geq 4 \mathrm{~mm}$ at 3-4 sites in more than 4 teeth in each quadrant and radiographic evidence of bone loss. Inclusion criteria for Group-B were absence of clinical gingival inflammation, PPD of $\leq 3 \mathrm{~mm}$ and CA loss of $\leq 1 \mathrm{~mm}$ (31). Patients with history of any systemic diseases, smoking, use of tobacco in any form, alcoholism, pregnancy, presence of any gross pathology and also patients who have received any periodontal therapy in past 12 months or any antioxidant supplements, vitamin intake, anti- microbial, anti- inflammatory and immune suppressive therapy in the past 6 months were excluded. 
Patients with less than 20 teeth present in the oral cavity, those who regularly used mouth wash and those who did not give their consent for the study were also excluded.

\section{(B) Clinical Examination}

All the clinical parameters were assessed after sample collection to avoid contamination of the samples. The readings were noted by a trained and calibered examiner (PP). For each patient, Plaque index (PI) (32), Gingival index(GI) (33) , Probing pocket depth (PPD) and Clinical attachment loss (CA loss) were noted at 6 sites (mesiobuccal, buccal, distobuccal, mesiolingual, lingual and distolingual) on each tooth excluding third molars using a sterile Hu-Friedy (UNC-PCP15) probe. Reproducibility of data was checked and were found to be $>90 \%$ accurate.

The independent variables of this study were; age, sex, education, income, and socio- economic status (SES), frequency of use of oral hygiene aid and number of teeth present in the oral cavity. Modified Prasad classification (34) was used to assess SES which divides it into 5 classes according to per capita monthly income.

(C) Collection of clinical samples- All samples prior to and after NSPT, were collected the following morning after patients had fasted overnight. Patients were asked to refrain from brushing and drinking anything in the morning except water. Before sample collection, it was made sure that the individuals adhered to the aforementioned protocol.

(D) Collection of saliva - Two milliliters of whole unstimulated saliva samples were collected by modified draining method for $5 \mathrm{~min}$, Miller et al (35). Saliva samples were centrifuged at $4000 \mathrm{rpm}$ for $10 \mathrm{~min}$ to remove cell debris. The $0.5 \mathrm{ml}$ of supernatant was stored in $1.5 \mathrm{ml}$ aliquots, having a tracking number, at $80^{\circ} \mathrm{C}$ until analysis.

(E) Collection of plasma -Two milliliters of blood was collected from the antecubital fossa by venipuncture using 20- gauge needle with a $5 \mathrm{ml}$ syringe and transferred into purple top EDTA tube for plasma separation. Plasma samples were centrifuged at $2000 \mathrm{rpm}$ at $4^{\circ} \mathrm{C}$ for 20 minutes. $0.5 \mathrm{ml}$ of extracted plasma was immediately transferred to $1.5 \mathrm{ml}$ aliquots. Each aliquot was designated a tracking number and stored at $-80^{\circ} \mathrm{C}$ until further analysis.

\section{(F) Lysate Preparation-}

Plasma was then transferred to separate sterile tubes. The pellet (RBC) was found intact in bottom of the tube, which was washed at least twice with normal saline $(0.9 \%)$. Further, chilled distilled water was added equal to the amount of ruptured RBC separated. Now centrifugation at 10,000 rpm for $20 \mathrm{~min}$ was performed to collect the supernatant (lysate) and discard the pellet (cell debris). Lysate were stored at $-80^{\circ} \mathrm{C}$ until subjected to biochemical analysis.

\section{(G) Estimation of Superoxide dismutase (SOD) (Mc Cord and Fridovich, 1969) (36)}

Nicotinamidedinucleotide (NADH) in the presence of phenozinemethosulphate (PMS) generates superoxide radical which reduces the nitrobluetetrazolium (NBT) and form formazon having dark blue colour. When SOD source (saliva or RBC lysate) is added to above reaction mixture these participates in another reaction to neutralize $\mathrm{O}_{2}{ }^{-}$into $\mathrm{H}_{2} \mathrm{O}_{2}$ and therefore first reaction; the reduction of NBTslows down and which indicates measure of the SOD activity. The unit of SOD enzyme activity is defined as the amount of enzyme required to inhibit the optical density at $560 \mathrm{~nm}$ of NBT reduction by $50 \%$ in 1 minute under the assay conditions. The results are expressed as unit per ml of lysate or saliva.

\section{(H) Periodontal Intervention}

In Group A, patients were subjected to full-mouth scaling and root planing by periodontal scalers and curettes (Hu-Friedy). The treatment consisted of four 45-minute sessions over a period of 3 weeks. Oral hygiene instructions were reinforced in each appointment. The patients were instructed to use only mechanical plaque removal methods i.e. toothbrushes and interdental cleaning aids during the study period, mouthwashes and /or 
antimicrobials were not prescribed during the study period. On first and second recall visits at 3 and 6 months respectively, sample collection and clinical parameter recording were again repeated and oral hygiene instructions were reinforced. For ethical reasons, subjects included in the study received nonsurgical and supportive periodontal treatment if necessary, after completion of the study.

\section{Data Analysis}

Descriptive statistics such as mean and standard deviation (SD) for continuous variables and frequency $\&$ percentage for categorical variables were determined. The categorical/dichotomous variables were compared by using Chi-square/Fisher exact test. The parameters at baseline were compared using the unpaired $t$-test and paired t-test was used to compare the changes in the parameters from baseline to 4 and 8 week. The correlation coefficient in Group- A was calculated among the parameters at baseline. The average percent change was calculated as (baseline value-follow-up value)/baseline X 100. The p-value $<0.05$ was considered as significant. All the analysis was carried out by using SPSS 16.0 version (Chicago, Inc. USA).

\section{Results}

(A) Subject characteristics:

Table 1 reveals no statistically significant differences $(p>0.05)$ between the two groups in terms of independent variables.

\section{(B) Cross sectional findings of the study:}

All the clinical parameters (PI, GI, PPD and CA loss) were significantly higher in group A as compared to group B at baseline and the difference in their means was statistically significant $(\mathrm{p}<0.05)$. The samples in each group tested positive for SOD activity. At baseline, the mean SOD levels in saliva and plasma of group-A $(19.36 \pm 8.40 \mathrm{U} / \mathrm{ml}, 24.60 \pm 8.62 \mathrm{U} / \mathrm{ml})$ were significantly lower when compared to group-B $(36.22 \pm 9.53 \mathrm{U} / \mathrm{ml}$, $43.06 \pm 16.89 \mathrm{U} / \mathrm{ml})$ respectively and the intergroup difference in means were statistically significant $(\mathrm{p}<0.05)$ as depicted in Table 2.

Table 3 shows, significant negative correlation $(\mathrm{p}<0.01)$ between SOD levels in saliva $(+1.000)$, PI, PPD \& CA Loss $(-0.708,-0.758 \&-0.649)$ respectively. SOD levels in plasma showed significant negative correlation with PI and PPD $(\mathrm{p}<0.01)$. However, SOD levels in plasma and saliva had significant positive correlation $(\mathrm{p}<0.01)$ with each other.

\section{(C) Longitudinal findings of the study:}

Table-4 depicts that periodontal parameters improved significantly from baseline at both the recall visits in CP patients. The mean values of SOD saliva and SOD plasma at baseline were $19.36 \pm 8.40$ \& $24.60 \pm 8.62 \mathrm{U} / \mathrm{ml}$ respectively. Both the biochemical parameters showed a marked increase in their respective values at 3 months $(29.04 \pm 9.58,59.92 \pm 16.89 \mathrm{U} / \mathrm{ml})$ and at 6 months $(32.43 \pm 9.51,66.79 \pm 15.63 \mathrm{U} / \mathrm{ml})$.

Figure- 1 unveils a linear diagrammatic representation of average percent change in all the assessed parameters from baseline to 3 and 6 months. PPD decreased by 37.7\% from baseline to 3 months and $60.5 \%$ from baseline to 6 months. CA Loss decreased by $12.2 \%$ from baseline to 3 months and $28.3 \%$ from baseline to 6 months. Salivary SOD levels increased upto $9.8 \%$ from baseline to 3 months and $25.7 \%$ from baseline to 6 months. The increase in plasma SOD from baseline to 4 week was $60.6 \%$ and at 6 months was $65.1 \%$.

\section{Discussion}

Aerobic life is characterized by steady formation of ROS (37) which acts as a double edged sword as it is an essential component of the host response to insults such as periopathogens (38) and if kept unchecked damages critical bio-molecules such as proteins, lipids and DNA (39). There has been absolutely no documented evidence investigating the whereabouts and potentiality of ROS as they have an abbreviated half life (14). Hence the majority of research has focussed upon measuring the by-products arising from interaction between ROS and bio molecules such as lipids (Thiobarbituric acid reactive substances, TBARS in gingival biopsies: Halliwell \& Whiteman(40), Panjamurthy et al, (10); Malondialdehyde, MDA in GCF: Tsai et al,(41), DNA (8- 
OHdG, 8-hydroxydeoxyguanosine: Takane et al,(42) Sugano et al, (43) and proteins (saliva protein carbonyls: Scully \& Langley-Evans(19).

In our study we opted to evaluate a specific AO profile, superoxide dismutase pertaining to the fact that total anti-oxidant capacity (TAOC) assays bear low sensitivities and may overlook the importance of an essential AO for a particular biological system.

SOD has been localized within human periodontal ligament (13) and may represent an important defense mechanism within gingival fibroblasts against superoxide release (44). The idea of selecting saliva as the medium for evaluation of SOD in our study stemmed from the fact that saliva may constitute the first line of defence against free radical mediated oxidative stress in oral cavity (45).

The longitudinal study under consideration reveals no disparity $(\mathrm{p}>0.05)$ amongst the study population in terms of socio demographic characteristics (Table-1). This was done to curtail the bias arising from ageing (46). It is imperative to understand the SES of the study population in order to correlate its impact on periodontal health. The purpose of using Modified Prasad's classification is that it takes into consideration only the per capita monthly income as a variable and can be applied to both rural and urban populations. Smokers were excluded from the study keeping in view their negative impact over AO profile (47).

At baseline, all the clinical parameters were found to be significantly higher in group-A than in groupB $(p<0.05)$. Saliva being an extracellular fluid contains low levels of SOD but all the samples in this study tested positive showing the efficiency of the method used. Salivary SOD levels were noted to be significantly lower in $\mathrm{CP}$ group than in PH group ( $\mathrm{p}<0.05)$. Our results are in accordance to studies by Singh et al, (30) they used SOD ELISA kit and found median salivary SOD levels to be $10.95 \mathrm{U} / \mathrm{ml}$ in chronic periodontitis subjects as compared to $21.66 \mathrm{U} / \mathrm{ml}$ in healthy controls. Trivedi et al,(48) reported lowest salivary SOD levels in diabetic, periodontally healthy subjects $(13.45 \pm 2.80 \mathrm{U} / \mathrm{ml})$ and highest in healthy controls $(29.64 \pm 6.98 \mathrm{U} / \mathrm{ml})$ however, SOD mean values in chronic periodontitis patients fell in between them $(19.93+12.05 \mathrm{U} / \mathrm{ml})$. On the contrary Wei et al, (29) revealed higher salivary SOD levels in CP patients $(216.4+36.78 \mathrm{U} / \mathrm{mg}$ protein) than controls (174.9+21.07) which they attributed to an overall increased oxidant status of CP group. Similar trend was noticed with plasma SOD concentration in CP group as compared to PH group $(24.60 \pm 8.62 \mathrm{U} / \mathrm{ml}$, $43.60 \pm 16.89 \mathrm{U} / \mathrm{ml})$. Sobaniec and Sobaniec- Lotowska, (49) in an experimental study also found decreased serum SOD activity in perodontitis models. Our results are in harmony with Trivedi et al,(48), Singh et al,(30) and Baltaciog $` l u$ et al,(50) who also found decreased serum SOD levels in periodontitis patients (around 1.25 $\mathrm{U} / \mathrm{ml}$ ) than healthy controls (around $1.6 \mathrm{U} / \mathrm{ml}$ ), least serum SOD levels were noted in post menopausal chronic periodontitis patients (about $1 \mathrm{U} / \mathrm{ml}$ ), . Contrasting results were found by Aziz et al, (51) who noted higher RBC SOD activity in CP subjects and Wei et al, (29) who noted similarly higher SOD levels in serum of CP patients. In periodontitis, primary acute host defense cells (PMN's) are activated as a two - stage process upon encountering periopathogens (P.gingivalis, A.actinomycetemcomitans) and their antigens, present in gingival sulcus or in the blood stream, consisting of priming and full scale activation. Primed neutrophils demonstrate elevated level of ROS which shifts the said ecological balance in favour of pro-oxidant species leading to increased utilization of SOD. Several observations about oxidant-antioxidant imbalance in the pathological process of periodontitis have been documented in literature. Ellis et al, (25) and Akalin et al, (52) found decreased gingival SOD activity in periodontitis groups than the matched controls. Chapple et al, (53) and Brock et al, (17) evaluated plasma TAOC and found it to be lower in periodontitis patients than of healthy controls. On the contrary, Kawamoto et al, (54) noted a decrease in the salivary TAOC over the course of menstrual cycle in women with periodontitis.

There has been absolutely no documented evidence in human studies correlating the local and systemic levels of SOD with periodontal clinical parameters which makes our study the first to report such correlation. We found a strong negative correlation $(\mathrm{p}<0.05)$ between salivary SOD and PI, PPD and CA loss $(-0.708$,$0.758,-0.649$ respectively). We also noted a similarly strong negative correlation between plasma SOD, PI and PPD (+1.000, -0.666,-0.666). However, a strong positive correlation existed between plasma and salivary SOD which reflects systemic repercussions of periodontitis induced oxidative stress as supported in systematic review by Paraskevas et al, (55) who affirmed that chronic periodontitis induces a state of systemic inflammation. Ekuni D et al, (56) in an animal model demonstrated that periodontitis induced lipid peroxidation may be involved in the early stage of atheroscelorosis. On the contrary Esen C et al, (57) concluded that systemic OS is not affected by periodontitis. 
Tamaki et al, (58) demonstrated a positive co-relation of serum reactive oxygen metabolite (ROM) with progression of periodontitis and an increase antibody titre towards P.gingivalis, P. Intermedia and E.corrodens. Pavlica et al, (59) in an animal study also found negative correlation between serum, GCF TAOC and clinical parameters.

The longitudinal aspect of our study involved treating CP patients with non surgical periodontal therapy (NSPT) and following them at 3 and 6 months to check for sustainability of results.We came across significant improvement in all the clinical parameters at 3 months and results were upheld till 6 months with an average percent change in PPD and CA loss of $60.5 \%$ and $28.3 \%$ respectively from baseline to 6 months. The SOD activity in saliva also experienced an upsurge from baseline to 6 months with change of $25.7 \%$. A momentous improvement in SOD plasma levels were seen with a percent change of $65.1 \%$ at 6 months making our study stand out as the post treatment values outmatched those of healthy controls. Our results are in agreement with Singh et al, 2013 who reported insignificant improvement in serum and salivary SOD activity at 3 months after NSPT. Huang et al, (20) and Sukhtankar et al, (60) also reported improvement via. NSPT in the levels of respective AO studied. Toker et al, (61) and Grant et al,(28) noted no change in the AO profile studied. This finding in our study signifies the role of NSPT in reducing oxidative stress locally and systemically. This may be caused due to decreased bacterial load post NSPT thereby decreasing the prevailing inflammation,reducing ROS production and potentiating the body defence to restore the physiologic proantioxidant balance. Therefore it becomes inevitable to study the antioxidant defence profile which may further open doors for novel therapeutic approaches.

Within the constraints of this study it would not be erroneous to conclude that periodontitis negatively affects the level of SOD both locally as well as systemically predisposing the human body to oxidative stress associated disorders. Successful NSPT is highly effective in restoring SOD activity, hence defending its badge of the gold standard periodontal therapy. However, comprehensive large size longitudinal studies are needed which will further enhance our knowledge on SOD role in periodontal health \& disease.

\section{Conclusion}

These data suggest that SOD levels in saliva and plasma are compromised in periodontitis. SOD levels are correrelated with periodontal parameters delineating the importance of SOD in periodontal health. Non surgical periodontal therapy was able to restore the levels of SOD during follow-ups.

\section{Acknowledgement}

The authors extend their regards to the subjects who participated in the investigation. The authors also extend their thanks to Dr. Kishlay Bhartiya, Post Graduate Student, Dept of Periodontology for his valuable contribution in the study.

\section{References}

[1]. Devasagayam, TPA; Tilak JC, Boloor KK, Sane Ketaki S, Ghaskadbi Saroj S, Lele RD (2004). "Free Radicals and Antioxidants in Human Health: Current Status and Future

[2]. Prospects". Journal of Association of Physicians of India (JAPI) 52: 796.McCord JM. (2000). The evolution of free radicals and oxidative stress. Am J Med ; 652- 659 .

[3]. Chapple ILC (1997) Reactive oxygen species and antioxidants in inflammatory diseases. J Clin Periodontol ; 24:287-296.

[4]. Page RC, Engel LD, Narayanan AS, Clagett JA (1978) Chronic inflammatory gingival and periodontal disease. JAMA 11:545-550.

[5]. March, P. D. \& Devine, D. (2011) How is the development of dental biofilms influenced by the host? Journal of Clinical Periodontology 38 (S11), 28-35.

[6]. Van Dyke, T. E. (2007) Cellular and molecular susceptibility determinants for periodontitis.Periodontology $200045,10-13$.

[7]. Passo SA, Syed SA, Silva J. (1982) Neutrophil chemiluminescence in response to Fusobacterium nucleatum. J Periodontal Res 17:604-613.

[8]. Halliwell B.(2000). Oral inflammation and reactive species: a missed opportunity? Oral Dis ;6: $136-137$.

[9]. Gustafsson A, Asman B (1996) Increased release of free oxygen radicals from peripheralneutrophils in adult periodontitis after Fca-receptor stimulation. J Clin Periodontol ;23: 38-44.

[10]. Panjamurthy K, Manoharan S, Ramachandran C.R. (2005). Lipid peroxidation and antioxidant status in patients with periodontitis. Cell Mol Biol Lett ; 10: 255-264.

[11]. Buduneli N, Kardesler 1, Isik H, Wilis C.S. (2006) Effects of smoking and gingival inflammation on salivary antioxidant capacity. J Clin Periodontol ;33:159-164. 
[12]. Akalin F.A, Baltacioglu E, Alver A, Karabulut A.( 2007) Lipid peroxidation levels and total oxidant status in serum, saliva and gingival crevicular fluid in patients with chronic periodontitis. J Clin Periodontol ; 34: 558-565

[13]. Jacoby BH, Davis L. (1991).The electron microscopic immunolocalization of a copper-zinc superoxide dismutase in association with collagen fibres of periodontal soft tissues. J Periodontol ; $62: 413-420$.

[14]. Chapple \& John B. Matthews (2007) The role of reactive oxygen and antioxidant species in periodontal tissue destruction Periodontology 2000, 43, 160-232.

[15]. Ames BN, Shigenaga MK, Hagan TM.(1993) Oxidants, antioxidants, and the degenerative diseases of aging. Proc Natl Acad Sci U S A: 90: 7915-7922.

[16]. Halliwell B, Gutteridge JM (1989).Free radicals in biology and medicine. Oxford, UK: Oxford University Press.

[17]. Brock G.R, Butterworth M.J, Matthews J.B, Chapple I.L.C.(2004) Local and systemic total antioxidant capacity in periodontitis and health. J Clin Periodontol ;31: 515-521.

[18]. Amarasena N, Ogawa H, Yoshihara A, Hanada N, Miyaxaki H.(2005) Serum vitamin C-periodontal relationship in communitydwelling elderly Japanese. J Clin Periodontol : 32 : 93-97.

[19]. Sculley DV, Langley-Evans SC. (2003) Periodontal disease is associated with lower antioxidant capacity in whole saliva and evidence of increased protein oxidation. Clin Sci : 105: 167-172.

[20]. Huang P, Su T, Wang H.(2000) The relationship between GPx activity in gingival fluid and clinical parameters of adult periodontitis. Hua Xi Kou Qiang Yi Xue Za Zhi : 18: 106-108

[21]. Chang YC, Lai C-C, Lin L-F, Ni W-F, Tsai C-H.( 2005) The upregulation of heme oxygenase-1 expression in human gingival fibroblasts stimulated with nicotine. J Periodontal Res : 40: 252-257.

[22]. Akalin FA, Toklu E, Renda N. ( 2005) Analysis of superoxide dismutase activity levels in gingiva and gingival crevicular fluid in patients with chronic periodontitis and periodontally healthy controls. J Clin Periodontol : 32: 238- 243.

[23]. Curnutte, J. T. \& Babior, B. M. (1987) Chronic granulomatous disease. Advances in Human Genetics 16 ,239-245.

[24]. Waddington RJ, Moseley R, Embery G.( 2000) Reactive oxygen species: a potential role in the pathogenesis of periodontal diseases. Oral Dis ;6: 138-151.

[25]. Ellis SD, Tucci MA, Serio FG, Johnson RB.( 1998) Factors for progression of periodontal diseases. J Oral Pathol Med : 27: 101105 .

[26]. Canakci V, Yildrim A, Canakci F.C, Eltas A.( 2007) Total antioxidant capacity and superoxide dismutase activity levels in serum, saliva and gingival crevicular fluid in preeclamptic women with and without periodontal disease. J Periodontal ;78 : $1602-1611$.

[27]. Akalin F.A, Baltacioglu E, Alver A, Karabulut E.( 2009) Total antioxidant capacity and superoxide dismutase activity levels in serum and gingival crevicular fluid in pregnant women with chronic periodontitis. J Periodontol ;80: 457-467.

[28]. Grant MM, Brock GR, Matthews JB, Chapple ILC.( 2010) Crevicular fluid glutathione levels in periodontitis and the effect of nonsurgical therapy. J Clin Periodontol ; 37:17-23.

[29]. Wei D, Zhang XL,Wang YZ, Yang CX, Chen G.( 2010) Lipid peroxidation levels, total oxidant status and superoxide dismutase in serum, saliva, Gingival crevicular fluid in chronic periodontitis patients before and after periodontal therapy. Aust Dent J; 55(1):708 .

[30]. Singh N, Narula SC, Sharma RK, Tewari S, Sehgal PK.( 2013) Vitamin E Supplementation, Superoxide Dismutase Status and Outcome of Scaling and Root Planing inChronic Periodontitis Patients: A Randomized Clinical Trial. J Periodontol. 2013 May 20. [Epub ahead of print].

[31]. Alpagot T, Wolff LF, Smith QT, Tran SD.(1996) Risk indicators for periodontal disease in a racially diverse urban population. J Clin Periodontol; 23(11), 982-8.

[32]. Silness J, Loe H. (1964) Periodontal disease in pregnancy. Correlation between oral hygiene and periodontal condition. Acta Odontal. Scand ; $22,121-135$

[33]. Loe H, Silness J.(1963) Periodontal disease in pregnancy. I. Prevalence and severity. Acta Odontol Scand ; 21, $533-551$.

[34]. Shankar Reddy Dudala1, Arlappa .(2013) An Updated Prasad's Socio Economic Status Classification for 2013., www. ijrdh.com.

[35]. Miller Craig S, Joseph D Foley, and John T McDevitt Biomark.(2010) Current developments in salivary diagnostics. Med.; 4(1), 171-189.

[36]. Mc Cord JM, Fridovich I.( 1969) Superoxide dismutase : an enzymic function for erythrocuprein (hemocuprein) J Biol Chem ;244(22):6049-55

[37]. Sies H (1991) Oxidative Stress: Oxidants and Antioxidants. New York: Academic Press.

[38]. Fialkow L, Wang Y, Downey GP (2007). Reactive oxygen and nitrogen speciesas signaling molecules regulating neutrophil function. Free Radic Biol Med ; 42:153-164

[39]. Luqman, S. \& Rizvi, S. I. (2006) Protection of lipid peroxidation and carbonyl formation in proteins by capsaicin in human erythrocytes subjected to oxidative stress. Phytotherapy Research 20, 303-306.

[40]. Halliwell B, Whiteman M.( 2004) Measuring reactive species and oxidative damage in vivo and in cell culture: how should you do it and what do the results mean? Br J Pharmacol : $142: 231-255$.

[41]. Tsai CC, Chen HS, Chen SL, Ho YP, Ho KY, Wu YM, Hung CC. ( 2005) Lipid peroxidation: a possible role in the induction and progression of chronic periodontitis. J Periodontal Res : 40: 378-384.

[42]. Takane M, Sugano N, Iwasaki H, Iwano Y, Shimizu N.( 2002) New biomarker evidence of oxidative DNA damage in whole saliva from clinically healthy and periodontally diseased individuals. J Periodontol : 73: 551-554.

[43]. Sugano N, Kawamoto K, Numazaki H, Murai S, Ito K.( 2000). Detection of mitochondrial DNA mutations in human gingival tissues. J Oral Sci : $42:$ 221-223.

[44]. Skaleric U, Manthey CM, Mergenhagen SE, Gaspirc B, Wahl SM.( 2000) Superoxide release and superoxide dismutase expression by human gingival fibroblasts. Eur J Oral Sci : 108: 130-135.

[45]. Terao, J. \& Nagao, A. (1991) Antioxidative effect of human saliva on lipid peroxidation. Agricultural Biological Chemistry 55, 869-872. 
[46]. Culter R.G.( 1991) Antioxidant and aging. Am J Clin Nutr ;53: 373-379.

[47]. Zappacosta B, Persichilli S, Mordente A, Minucci A, Lezzaro D, Meucci E, Giardina B.( 2002) Inhibition of salivary enzymes by cigarette smoke and the protective role of glutathione. Human Exp Toxicol : 21: 7-11.

[48]. Trivedi DS, Dr Nandlal, Ali Mahdi DA, Mittal DM, Singh MB, Pandey DS. Evaluation of Antioxidant Enzymes Activity and Malondialdehyde Levels in Chronic Periodontitis Patients with Diabetes. J Periodontol. 2013 Jul 29. [Epub ahead of print]

[49]. Sobaniec H, Sobaniec-Lotowska ME ( 2000). Morphological examinations of hard tissues of periodontium and evaluation of selected processes of lipid peroxidation in blood serum of rats in the course of experimental periodontitis. Med Sci Monit : 6: 875881.

[50]. Baltaciog `lu E, Akalin FA, Alver A, Balaban F, U“nsal M, Karabulut E.( 2006) Totalantioxidant capacity and superoxide dismutase activity levels in serum and gingival crevicular fluid in post-menopausal women with chronic periodontitis. J Clin Periodontol; 33: 385-392.

[51]. Aziz AS, Kalekar MG, Benjamin T, Suryakar AN, Prakashan MM, Bijle MNA.( 2013) Effect of Nonsurgical Periodontal Therapy on Some Oxidative Stress Markers in Patients with Chronic Periodontitis: A Biochemical Study. World J Dent ;4 (1):17-23.

[52]. Akalin FA, Işiksal E, Baltacioğlu E, Renda N, Karabulut E. (2008) Superoxide dismutase activity in gingiva in type-2 diabetes mellitus patients with chronic periodontitis Arch Oral Biol. ;53(1):44-52

[53]. Chapple IL, Brock G, Eftimiadi C, Matthews JB. ( 2002) Glutathione in gingival crevicular fluid and its relation to local antioxidant capacity in periodontal health and disease. Mol Pathol. Dec; 55(6):367-73.

[54]. Kawamoto A, Sugano N, Motohashi M, Matsumoto S, Ito K.( 2012) Relationship between salivary antioxidant capacity and phases of the menstrual cycle. J Periodont Res; 47: 593-598.

[55]. Paraskevas S, Huizinga JD, Loos BG (2008). A systematic review and metaanalyses on C-reactive protein in relation to periodontitis. J Clin Periodontol 35:277-290.

[56]. Ekuni D, Firth JD, Nayer T, Tomofuji T, Sanbe T, Irie K, Yamamoto T, Oka T, Liu Z, Vielkind J, Putnins EE.(2009) Lipopolysaccharide-induced epithelial monoamine oxidase mediates alveolar bone loss in a rat chronic wound model. Am J Pathol. 2009 Oct;175(4):1398-409.

[57]. Esen C, Alkan BA, Kırnap M, Akgül O, Işıkoğlu S, Erel O (2012) The effects of chronic periodontitis and rheumatoid arthritis on serum and gingival crevicular fluid total antioxidant/oxidant status and oxidative stress index. J Periodontol. 2012 Jun;83(6):773-9. doi: 10.1902/jop.2011.110420. Epub 2011 Nov 3.

[58]. Tamaki N, Hayashida H, Fukui M, Kitamura M, Kawasaki K, Nakazato M, Maeda T, Saito T, Ito HO.(2013) Oxidative stress and antibody levels to periodontal bacteria in adults: the Nagasaki Islands study. Oral Dis. 2013 Apr 30. doi: 10.1111/odi.12127. [Epub ahead of print]

[59]. Pavlica Z, Petelin M, Nemec A, Erzen D, Skaleric U.( 2004) Measurement of total antioxidant capacity in gingival crevicular fluid and serum in dogs with periodontal disease. Am J Vet Res: 65: 1584-1588.

[60]. Sukhtankar L, Kulloli A, Kathariya R, Shetty S (2013) Effect of non-surgical periodontal therapy on superoxide dismutase levels in gingival tissues of chronic periodontitis patients: a clinical and spectophotometric analysis. Dis Markers. 2013;34(5):305-11.

[61]. Toker H, Akpınar A, Aydın H, Poyraz O.( 2012) Influence of smoking on interleukin-lbeta level, oxidant status and antioxidant status in gingival crevicular fluid from chronic periodontitis patients before and after periodontal treatment. J Periodont Res ; 47: $572-577$.

\begin{tabular}{|c|c|c|c|c|c|}
\hline \multirow{2}{*}{ Charecterstic } & \multicolumn{2}{|c|}{ Group A (CP) } & \multicolumn{2}{|c|}{ Group B (PH) } & \multirow[t]{2}{*}{ p-value } \\
\hline & No. & $\%$ & No. & $\%$ & \\
\hline \multicolumn{6}{|l|}{ Age (years) } \\
\hline $35-45$ & 6 & 30.0 & 6 & 27.3 & \multirow{3}{*}{0.88} \\
\hline $46-55$ & 9 & 45.0 & 9 & 40.9 & \\
\hline$>55$ & 5 & 25.0 & 7 & 31.8 & \\
\hline \multicolumn{6}{|l|}{ Gender } \\
\hline Male & 9 & 45.0 & 14 & 63.6 & \multirow{2}{*}{0.22} \\
\hline Female & 11 & 55.0 & 8 & 36.4 & \\
\hline \multicolumn{6}{|l|}{ Education } \\
\hline Upto $8^{\text {th }}$ & 6 & 30.0 & 4 & 18.2 & \multirow{4}{*}{0.59} \\
\hline $9^{\text {th }}-12^{\text {th }}$ & 9 & 45.0 & 10 & 45.5 & \\
\hline $\begin{array}{l}\text { Diploma/ Graduation \& } \\
\text { above }\end{array}$ & 5 & 25.0 & 8 & 36.4 & \\
\hline \multicolumn{5}{|l|}{$\begin{array}{l}\text { SES }^{\#} \text { (Socio-economic } \\
\text { status) }\end{array}$} & \\
\hline I & 3 & 15.0 & 3 & 13.6 & \multirow{5}{*}{0.65} \\
\hline II & 7 & 35.0 & 8 & 36.4 & \\
\hline III & 3 & 15.0 & 6 & 27.3 & \\
\hline IV & 5 & 25.0 & 2 & 9.1 & \\
\hline $\mathrm{V}$ & 2 & 10.0 & 3 & 13.6 & \\
\hline \multicolumn{6}{|l|}{ No. of teeth } \\
\hline $21-24$ & 9 & 45.0 & 10 & 45.5 & \multirow{2}{*}{0.98} \\
\hline $25-28$ & 11 & 55.0 & 12 & 54.5 & \\
\hline
\end{tabular}


Effect of non surgical periodontal therapy on salivary and RBC lysate superoxide dismutase levels ....

$\begin{array}{lccccc}\text { Once } & 3 & 15.0 & 3 & 13.6 & \\ \text { Twice } & 13 & 65.0 & 14 & 63.6 & 0.97 \\ \text { More than twice } & 4 & 20.0 & 5 & 22.7 & \end{array}$

"Modified Prasad Classification for Socioeconomic Status

Table-2: Unpaired t-test for comparison of clinical and biochemical parameters of study population at baseline

$\begin{array}{llll}\text { Parameters } & \text { Group A (CP) } & \text { Group B (PH) } & \text { p-value } \\ \text { PI } & 1.78 \pm 0.40 & 0.33 \pm 0.27 & 0.001^{*} \\ \text { GI } & 1.92 \pm 0.20 & 0.38 \pm 0.53 & 0.001^{*} \\ \text { PPD (mm) } & 4.03 \pm 0.12 & 0.97 \pm 0.69 & 0.001^{*} \\ \text { CA Loss (mm) } & 3.74 \pm 1.11 & 0.65 \pm 0.61 & 0.001^{*} \\ \text { Saliva SOD (U/ml) } & 19.36 \pm 8.40 & 36.22 \pm 9.53 & 0.001^{*} \\ \text { Plasma SOD (U/ml) } & 24.60 \pm 8.62 & 43.06 \pm 16.89 & 0.001^{*}\end{array}$

PI-Plaque index; GI-Gingival index; PPD-Probing pocket depth; CA Loss-Clinical Attachment loss; SODSuperoxide dismutase; values are presented in mean $\pm \mathrm{SD}$; ${ }^{*}$ Significant at $\mathrm{p}<0.05$

Table-3: Results of Spearman's Rank correlation (r) coefficient between clinical parameters and SOD levels

\begin{tabular}{|c|c|c|c|c|c|c|c|}
\hline \multicolumn{8}{|c|}{ in Group-A } \\
\hline & & PI & GI & PPD & CAL & SOD saliva & SOD blood \\
\hline \multirow[t]{3}{*}{ PI } & Correlation Coefficient & 1.000 & & & & & \\
\hline & P-value & . & & & & & \\
\hline & $\mathrm{N}$ & 20 & 20 & & & & \\
\hline \multirow[t]{3}{*}{ GI } & Correlation Coefficient & .290 & 1.000 & & & & \\
\hline & P-value & .215 & . & & & & \\
\hline & $\mathrm{N}$ & 20 & 20 & & & & \\
\hline \multirow[t]{3}{*}{ PPD } & Correlation Coefficient & $.818^{* *}$ & .367 & 1.000 & & & \\
\hline & P-value & .000 & .111 & . & & & \\
\hline & $\mathrm{N}$ & 20 & 20 & 20 & & & \\
\hline \multirow[t]{3}{*}{ CA Loss } & Correlation Coefficient & $.785^{* *}$ & .284 & $.824^{* *}$ & 1.000 & & \\
\hline & P-value & .000 & .224 & .000 & . & & \\
\hline & $\mathrm{N}$ & 20 & 20 & 20 & 20 & 20 & \\
\hline \multirow[t]{3}{*}{ SOD saliva } & Correlation Coefficient & $-.708^{* *}$ & -.419 & $-.758^{* *}$ & $-.649^{* *}$ & 1.000 & \\
\hline & P-value & .000 & .066 & .000 & .002 & . & \\
\hline & $\mathrm{N}$ & 20 & 20 & 20 & 20 & 20 & \\
\hline \multirow[t]{3}{*}{ SOD plasma } & Correlation Coefficient & $-.666^{* *}$ & -.238 & $-.666^{* *}$ & -.437 & $.686^{* *}$ & 1.000 \\
\hline & P-value & .001 & .312 & .001 & .054 & .001 & . \\
\hline & $\mathrm{N}$ & 20 & 20 & 20 & 20 & 20 & 20 \\
\hline
\end{tabular}

PI-Plaque index; GI-Gingival index; PPD-Probing pocket depth; CA Loss- Clinical Attachment Loss;

$* *$ Significant at $\mathrm{p}<0.05$

Table-4: Paired t-test for evaluation of clinical and biochemical parameters in Group

A subjects at baseline and during follow ups

$\begin{array}{llll}\text { Parameters } & \text { Baseline } & \text { At 3 months } & \text { At 6 months } \\ \text { PI } & 1.78 \pm 0.40 & 1.14 \pm 0.41^{1} & 1.03 \pm 0.42^{1,2} \\ \text { GI } & 1.92 \pm 0.20 & 1.05 \pm 0.11^{1} & 0.96 \pm 0.04^{1,2} \\ \text { PPD (mm) } & 4.03 \pm 0.12 & 2.50 \pm 0.35^{1} & 1.58 \pm 1.05^{1,2} \\ \text { CA Loss (mm) } & 3.74 \pm 1.11 & 3.02 \pm 0.49^{1} & 2.51 \pm 1.14^{1,2} \\ \text { SOD Saliva (U/ml) } & 19.36 \pm 8.40 & 29.04 \pm 9.58^{1} & 32.43 \pm 9.51^{1,2} \\ \text { SOD Plasma (U/ml) } & 24.60 \pm 8.62 & 59.92 \pm 16.89^{1} & 66.79 \pm 15.63^{1,2}\end{array}$

Values are in mean $\pm \mathrm{SD},{ }^{1} \mathrm{p}<0.001$ (significant from baseline), ${ }^{2} \mathrm{p}<0.001$ (significant from 4 to 8 week) 
Effect of non surgical periodontal therapy on salivary and RBC lysate superoxide dismutase levels ....

Figure 1: Line diagram depicting average percent change in the parameters from Baseline to 3 and 6 months

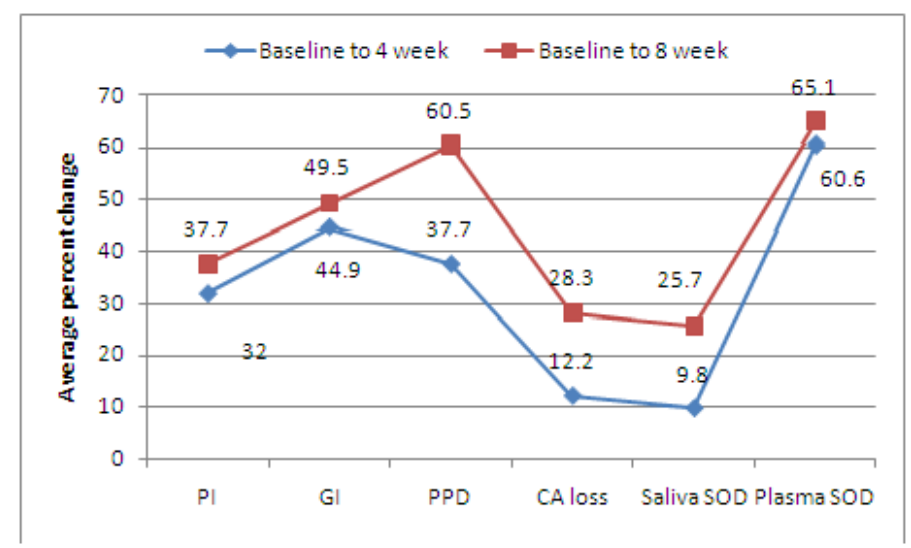

